\title{
curriculum descant
}

\section{Beyond Introductory AI}

$\mathrm{M}$

uch of the discussion on teaching artificial intelligence (AI) tends to be centered on the introductory course. Typically, introductory AI courses are offered in undergraduate programs at the junior or senior level. The underlying assumption is that such a course serves as a capstone to the learning experiences of a computer science student. In this installment, I would like to examine undergraduate courses that go beyond the standard introductory AI course.

It is important to recognize the diversity of computer science programs. Some undergraduate programs are part of an established graduate program; however, many programs are stand-alone undergraduate programs. Even programs that offer graduate degrees restrict the number of AI courses to more or less an introductory AI course, which is often crosslisted as a graduate-level course. This is true even in programs that are strong in $\mathrm{AI}$ research. Most AI courses that cover topics beyond the introductory course are designed for graduate students, but motivated undergraduate students can enroll in these courses. Occasionally, undergraduate students also undertake advanced work in AI research labs. Working together on a research project alongside graduate students is one of the most rewarding experiences for undergraduates.

For the majority of programs that offer only undergraduate-level instruction in computer science, the possibility of offering even an introductory course in AI can be an issue. There may be limited resources, high demands of faculty on other areas of the curriculum, or the limited availability of faculty who are willing to teach AI. The school may not have faculty whose research area is AI. Here, the definition of a core computer science curriculum plays an important role. If $\mathrm{AI}$ is prescribed by a standard curriculum (for instance, the ACM/IEEE Curriculum 1991 lists several AI and AI-related knowledge units), the likelihood of finding an AI course is greater.
Another parameter that can play an important part in determining the range of AI courses offered is the size of the program. Larger programs tend to have larger class enrollments. Sometimes, larger class sizes can limit the range of advanced courses offered. For instance, the use of LEGO-based robot labs (see "Curriculum Descant," SIGART Bulletin, Fall 1998) has been found to be more feasible in schools with smaller class sizes. Smaller class sizes also enable the creation of interdisciplinary AI courses that require active class participation. For example, I offer a course entitled Biologically Inspired Computational Models of Learning, which is cotaught with a professor of neurobiology. Topics range from studying the fundamentals of neural networks and genetic algorithms to evolutionary computation, with contributions and viewpoints from a biological perspective. The course inherently relies on smaller class sizes because it requires quite a bit of discussion and interaction.

Expanding to other disciplines on a campus can be a rewarding experience for both the faculty and students. Often, introductory AI courses can be found in psychology, information systems, linguistics, philosophy, and engineering programs. Other AI courses may be found in those programs that can extend the scope of any introductory AI course. In graduate school I took a course titled Introduction to Artificial Intelligence in the psychology department. The course used the same text (Charniak and McDermott) as the computer science offering; however, the syllabus and focus were entirely different. Whereas the computer science version concentrated on representation and algorithms, the psychology course focused on underlying cognitive studies and the feasibility of proposed models. Whether or not a computer science program offers an introductory AI course, similar offerings in other programs can help expand the options and increase the possibility of interdisciplinary collaborations.

\section{Deepak Kumar}

Department of

Mathematics and

Computer Science

Bryn Mawr College

Bryn Mawr, PA 19010

dkumar@brynmawr.edu

Permission to MAKe digital or HARD COPIES OF ALL OR PART OF THIS WORK FOR PERSONAL OR CLASSROOM USE IS GRANTED WITHOUT FEE PROVIDED THAT COPIES ARE NOT MADE OR DISTRIBUTED FOR PROFIT OR

COMMERCIAL ADVANTAGE AND THAT COPIES BEAR THIS NOTICE AND THE FULL CITATION ON THE FIRST PAGE. TO COPY OTHERWISE, TO REPUBLISH, TO POST ON SERVERS OR TO REDISTRIBUTE TO LISTS, REQUIRES PRIOR SPECIFIC PERMISSION AND/OR A FEE. (c) ACM 1523-8822 99/0900 \$5.00 